\title{
Curcumin Inhibits Adipogenesis Elicited by Clozapine in 3T3-L1 Cells
}

\section{Satoru Sakuma*, Maki Sumida, Asami Sakabe, Ayaka Nakamura, Chisato Noda, Tetsuya Kohda, Kaho Tsujimoto, Maimi Kobayashi, Tomohiko Sano, Yohko Fujimoto}

Department of Physiological Chemistry, Osaka University of Pharmaceutical Sciences, Osaka, Japan

Email: *sakuma@gly.oups.ac.jp

How to cite this paper: Sakuma, S., Sumida, M., Sakabe, A., Nakamura, A., Noda, C., Kohda, T., Tsujimoto, K., Kobayashi, M., Sano, T. and Fujimoto, Y. (2018) Curcumin Inhibits Adipogenesis Elicited by Clozapine in 3T3-L1 Cells. Food and Nutrition Sciences, 9, 584-594.

https://doi.org/10.4236/fns.2018.95044

Received: April 19, 2018

Accepted: May 21, 2018

Published: May 24, 2018

Copyright $\odot 2018$ by authors and Scientific Research Publishing Inc. This work is licensed under the Creative Commons Attribution International License (CC BY 4.0).

http://creativecommons.org/licenses/by/4.0/

\begin{abstract}
Although clozapine (CZP), which is used for schizophrenia treatment, causes weight gain, the mechanism remains unclear. We recently reported that the naturally occurring compound curcumin (CUR) suppresses adipogenesis in 3T3-L1 cells. The aims of the present study were to determine the mechanism by which CZP induces adipocyte differentiation of 3T3-L1 cells, and whether CUR reduces CZP-induced adipogenesis. We found that cells grown in the presence of CZP had significantly higher triacylglycerol levels, numbers of lipid-filled adipocytes, and mRNA expression levels of CCAAT-enhancer binding protein $\alpha(\mathrm{C} / \mathrm{EBP} \alpha)$ and peroxisome proliferator-activated receptor $\gamma$ $(\operatorname{PPAR} \gamma)$ than those grown without CZP. Treatment with CZP plus CUR resulted in major reductions in these four parameters. These results suggest that CZP enhances adipogenesis in 3T3-L1 cells via the C/EBP $\alpha$-PPAR $\gamma$ pathway and that by interrupting CZP's effects, CUR might be a potent agent for preventing CZP-induced weight gain.
\end{abstract}

\section{Keywords}

Clozapine, Curcumin, Adipocyte Differentiation, 3T3-L1 Cell, Atypical Antipsychotic Drug

\section{Introduction}

Clozapine (CZP) is a second-generation atypical antipsychotic drug used to treat many schizophrenia symptoms, such as positive symptoms, negative symptoms, and recognition disorders. The major side effects of CZP are weight gain and diabetes mellitus, which are risk factors for cardiovascular diseases [1]. The probable causes of the metabolic adverse effects are poor satiety and increased food intake due to blockade of receptors such as 5-hydroxytryptamine $2 \mathrm{C}$ 
(5 $\left.\mathrm{HT}_{2 \mathrm{C}}\right)$, dopamine $\mathrm{D} 2\left(\mathrm{D}_{2}\right)$, and histamine $1\left(\mathrm{H}_{1}\right)$ in the central nervous system [2]. In the last decade, it has been suggested that second-generation atypical antipsychotic drugs cause body weight gain not only by affecting the receptors of the central nervous system but also by directly affecting peripheral adipogenesis [3]-[8]. However, the mechanism by which second-generation atypical antipsychotic drugs directly induce adipocyte differentiation remains unclear.

Over the years, many phytochemical compounds have been found to have a high capacity to act against various disorders, including metabolic syndrome. One of these substances, curcumin (CUR), a nutraceutical and pharmaceutical, is the active ingredient in turmeric, a well-known Indian spice derived from the dried roots of the Curcuma longa plant. The effects of CUR in metabolic syndrome have been studied in several clinical trials. In these trials, CUR improved the lipid profiles and modified the cholesterol-related parameters of the subjects [9] [10]. Furthermore, CUR can improve anthropometric measurements and body composition when taken as part of the diet together with the implementation of appropriate lifestyle interventions [11].

3T3-L1 preadipocytes are extensively used as an in vitro model for studying adipogenesis. Our laboratory [12] and other groups [13] [14] [15] have reported that CUR suppresses the adipogenic differentiation of 3T3-L1 preadipocytes by downregulating the CCAAT-enhancer binding protein $\alpha(\mathrm{C} / \mathrm{EBP} \alpha)$-peroxisome proliferator-activated receptor $\gamma(\operatorname{PPAR} \gamma)$ pathway, which is a major adipogenesis pathway [16] [17]. Thus, the present study was designed to determine whether CZP induces adipocyte differentiation of 3T3-L1 cells via the C/EBP $\alpha$-PPAR $\gamma$ pathway. Furthermore, to our knowledge, this is the first study to evaluate whether CUR could interrupt CZP-induced adipogenesis.

\section{Materials and Methods}

\subsection{Materials}

Mouse 3T3-L1 preadipocytes were obtained from the European Collection of Cell Cultures (Wiltshire, UK). Transcriptor First Strand cDNA Synthesis kit and Light Cycler First Start DNA Master ${ }^{\text {plus }}$ SYBR green reagent were obtained from Roche Diagnostics (Indianapolis, IN, USA). TRIzol reagent and the primers for $\beta$-actin, PPAR $\gamma$, and C/EBP $\alpha$ were purchased from Invitrogen (Carlsbad, CA, USA). CZP, CUR, olanzapine (OZP), chlorpromazine (CPZ) and a protease inhibitor cocktail were obtained from Sigma Chemical Co. (St. Louis, MO, USA). The triglyceride E-test Wako kit was obtained from Wako Pure Chemical Industries, Limited (Osaka, Japan). Lipid Droplets Fluorescence Assay kit was obtained from Cayman Chemical Co. (Ann Arbor, MI, U.S.A.). All other reagents used were of analytical grade.

\subsection{Cell Culture}

3T3-L1 preadipocytes were cultured at $37^{\circ} \mathrm{C}$ in a humidified atmosphere of $5 \%$ $\mathrm{CO}_{2} / 95 \%$ air. The cells were maintained in a growth medium containing Dul- 
becco's modified Eagle's medium with $10 \%$ fetal bovine serum and $1 \%$ penicillin-streptomycin (growth medium). Cell differentiation was induced according to the protocol received with the 3T3-L1 preadipocytes obtained from the European Collection of Cell Cultures. The procedure was initiated 2 days after confluence and performed for 3 days in a growth medium containing $0.25 \mu \mathrm{M}$ dexamethasone, $0.5 \mathrm{mM} 3$-isobutyl-1-methylxanthine (IBMX), and $1 \mu \mathrm{g} / \mathrm{mL}$ insulin (initiation medium). This was followed by 2 days of culture in growth medium containing $1 \mu \mathrm{g} / \mathrm{mL}$ insulin (maturation medium). Thereafter, the cells were cultured in the growth medium for 2 days. Treatment with various drugs during the differentiation of the 3T3-L1 preadipocytes and subsequent Oil Red O staining, determination of triacylglycerol (TG) levels, and mRNA expression levels of PPAR $\gamma$ and $\mathrm{C} / \mathrm{EBP} \alpha$ were performed according to previously reported methods [12] [18] [19].

\subsection{Treatments with CZP and CUR}

CZP and CUR were prepared in dimethyl sulfoxide $\left(\mathrm{Me}_{2} \mathrm{SO}\right)$ and added to the growth, initiation, and maturation media from day 3 (time of addition of dexamethasone, IBMX, and insulin) to day 9 (the end of the experiment). The $\mathrm{Me}_{2} \mathrm{SO}$ concentration was maintained up to $0.25 \%$ of the total volume of the medium. Preliminary experiments demonstrated no significant effects of $0.25 \%$ $\mathrm{v} / \mathrm{v} \mathrm{Me}_{2} \mathrm{SO}$ on cell differentiation.

\subsection{Oil Red O Staining}

The cells were fixed in $4 \%$ formaldehyde-phosphate buffer ( $\mathrm{pH} \mathrm{7.4)} \mathrm{for} 1 \mathrm{~h}$, rinsed with water, and stained with $0.3 \%$ Oil Red $\mathrm{O}$ dye for $1 \mathrm{~h}$. After washing again with water, the cells were monitored using a microscope $(10 \times 20$ magnification).

\subsection{Quantification of Mature Adipocytes}

Mature adipocytes in the culture were quantified using Lipid Droplets Fluorescence Assay kit, and flow cytometry. The cells were trypsinized carefully and centrifuged at $4^{\circ} \mathrm{C}$ and $200 \times g$ for $5 \mathrm{~min}$. The cell pellet was resuspended, fixed, and stained with the lipophilic fluorescent dye Nile Red according to the protocol received with Lipid Droplets Fluorescence Assay kit. The samples were then analyzed with a FACSAria III flow cytometer (Becton Dickinson, Basel, Switzerland). Nile Red fluorescence was measured on the FL2 emission channel through a $585 \pm 21 \mathrm{~nm}$ bandpass filter following excitation with an argon ion laser source at $488 \mathrm{~nm}$. Using a forward scatter (FSC)/side scatter (SSC) representation of events, the P1 region was defined to exclude cellular debris from the analysis. A selection window called P2 was then established on the FL2/FSC blot of the P1 population to count cells with high FL2 values (mature adipocytes) as described by Sottile and Seuwen [20]. Data analysis was performed using BD FACSDiva Software ver. 8.0 (Becton Dickinson). For each sample, 20,000 events 
were collected. The results are expressed as the percentage of cells in the P2 region.

\subsection{Determination of TG Levels}

The cells were harvested by scraping them from the culture dishes into lysis buffer (1\% Triton-100, $150 \mathrm{mM} \mathrm{NaCl}, 4 \mathrm{mM}$ ethylenediaminetetraacetic acid, and $20 \mathrm{mM}$ Tris- $\mathrm{HCl}$ [pH 7.4] containing a protease inhibitor cocktail) and lysed completely using a horn-type sonicator. The TG level, which is an index of lipid accumulation, was determined using Triglyceride E-test Wako kit following normalization of the protein amounts and expressed as TG content ( $\mu \mathrm{g} / \mathrm{mg}$ protein).

\subsection{Determination of the mRNA Expression Levels of $\beta$-Actin, PPAR $\gamma$, and C/EBP $\alpha$}

Untreated cells, as well as those treated with CZP or CZP plus CUR up to day 5, were washed with ice-cold phosphate-bufferedsaline. Total cellular RNA was prepared using TRIzol reagent. One microgram of total RNA was reverse-transcribed into cDNA by using the Transcriptor First Strand cDNASynthesis kit. Next, the concentration and quality of the purified total RNA were determined spectrophotometrically at $260 \mathrm{~nm}$ and by the $\mathrm{OD}_{260: 280}$ ratio. mRNA expression was determined by real-time reverse transcription polymerase chain reaction using Light Cycler First Start DNA Master ${ }^{\text {plus }}$ SYBR Green reagent and a Light Cycler instrument. The results are expressed as the target mRNA level relative to that of $\beta$-actin mRNA, and the values obtained in the presence or absence of the drugs were expressed relative to the values associated with exposure to the differentiation medium (DM) alone.

The primers used for $\beta$-actin, PPAR $\gamma$, and $\mathrm{C} / \mathrm{EBP} \alpha$ were as follows: $\beta$-actin, 5'-ACACCCCAGCCATGTACG-3', 5'-TGGTGGTGAAGCTGTAGCC-3'; PPAR $\gamma$, 5'-GTGAAGCCCATCGAGGACA-3', 5'-TGGAGCACCTTGGCGAACA-3'; and C/EBP $\alpha, 5^{\prime}$-ATGGTTTCGGGTCGCTGGAT-3', 5'-CCACGGCCTGACTCCCTCAT-3'.

\subsection{Statistical Analysis}

The results are expressed as the mean \pm standard error of the mean values. Significant differences in data between two groups were assessed using Student's $t$-test. Differences were considered statistically significant at $P<0.05$.

\section{Results}

\subsection{CZP Promotes the Differentiation of 3T3-L1 Cells}

Figure 1(a) shows the effect of CZP, OZP and CPZ at concentrations ranging from 1 to $20 \mu \mathrm{M}$ on TG level during the differentiation of 3T3-L1 preadipocytes into mature adipocytes. Exposure to the second-generation atypical antipsychotics CZP and OZP increased TG levels, whereas exposure to CPZ, a classical neuroleptic drug that primarily acts on dopamine $\mathrm{D}_{2}$ receptors, did not. At $5 \mu \mathrm{M}$, 


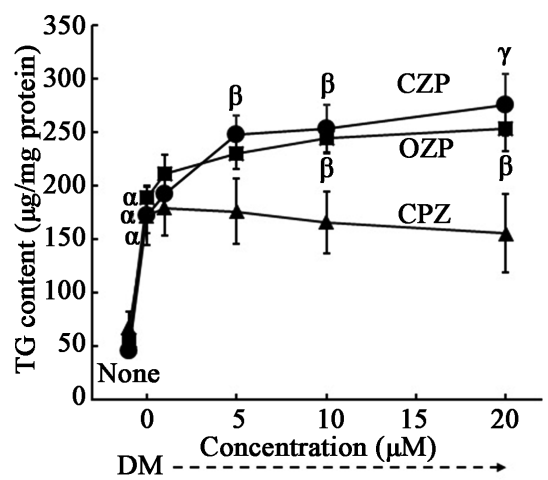

(a)

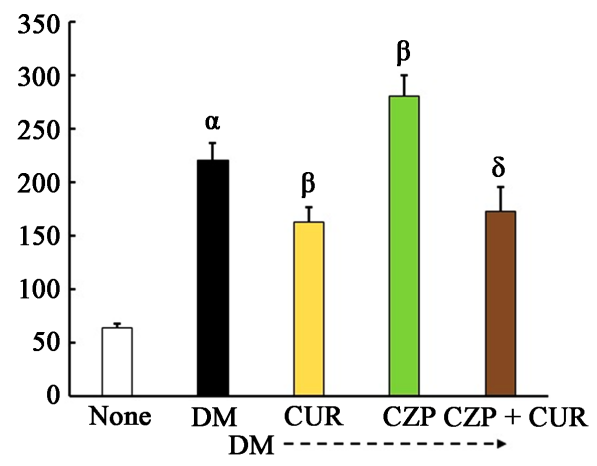

(b)

Figure 1. Alterations in triacylglycerol (TG) levels in 3T3-L1 adipocytes treated with clozapine (CZP), olanzapine (OZP), chlorpromazine (CPZ), and curcumin (CUR). (a) Data are presented as mean \pm standard error of the mean values $(n=3-8)$; (b) Data are presented as mean \pm S.E. values $(\mathrm{n}=19-23)$. CZP, $20 \mu \mathrm{M}$; CUR, $20 \mu \mathrm{M}$. ${ }^{\alpha}$ indicates $P<0.01$ compared to the untreated cells (None). ${ }^{\beta}$ indicates $P<0.05$ and $\gamma_{\text {indicates }} P<0.01 \mathrm{com}$ pared to the cells cultured in the differentiation medium (DM). ${ }^{\delta}$ indicates $P<0.01$ compared to the cells treated with CZP alone.

CZP, but not OZP, promoted TG accumulation with statistical significance. The findings show that second-generation atypical antipsychotic drugs cause body weight gain partially by affecting peripheral adipogenesis directly. This result is in agreement with results of previous studies [3]-[8].

\subsection{CUR Interferes with CZP-Induced Adipogenesis in 3T3-L1 Cells}

To study the potential inhibitory effects of CUR on CZP-induced adipogenesis, $20 \mu \mathrm{M}$ CUR was added to the culture medium together with CZP $(20 \mu \mathrm{M})$ during the differentiation of the 3T3-L1 cells. Changes in differentiation were monitored by determining the TG levels (Figure 1(b)), Oil Red O staining (Figure $2(\mathrm{a})$ ), and determining the percentage of mature adipocytes (Figure 2(b) and Figure 2(c)).

Compared to exposure to DM alone, exposure to both $20 \mu \mathrm{M} \mathrm{CZP}$ and DM resulted in a significant increase in TG levels (1.3 fold in Figure 1(b)), Oil Red O-stained cells (Figure 2(a)), and percentage of lipid-filled adipocytes as shown by Nile Red and flow cytometry (2.4 fold in Figure 2(c)). However, the administration of $20 \mu \mathrm{M}$ CUR with CZP almost nullified the effects of CZP; the TG levels (Figure 1(b)), number of Oil Red O-stained cells (Figure 2(a)), and percentage of lipid-rich adipocytes (Figure $2(c)$ ) were similar to the respective levels in the presence of DM or CUR alone. The results shown in Figure 1(b) and Figure 2 demonstrate that CUR interferes with the CZP-induced adipogenesis in 3T3-L1 cells.

\subsection{CUR Disrupts the Effect of CZP at the Site of the $\mathrm{C} / \mathrm{EBP} \alpha-\mathrm{PPAR} \gamma$ Pathway}

As shown in Figure 3(a) and Figure 3(b), compared to exposure to DM alone, 


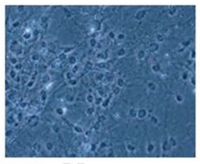

None

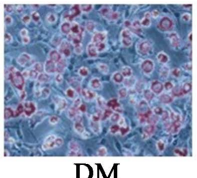

DM

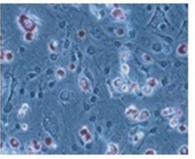

DM+CUR

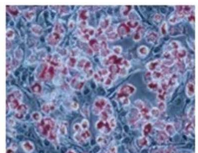

$\mathrm{DM}+\mathrm{CZP}$

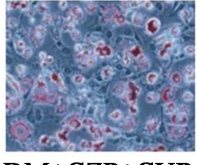

$\mathrm{DM}+\mathrm{CZP}+\mathrm{CUR}$

(a)
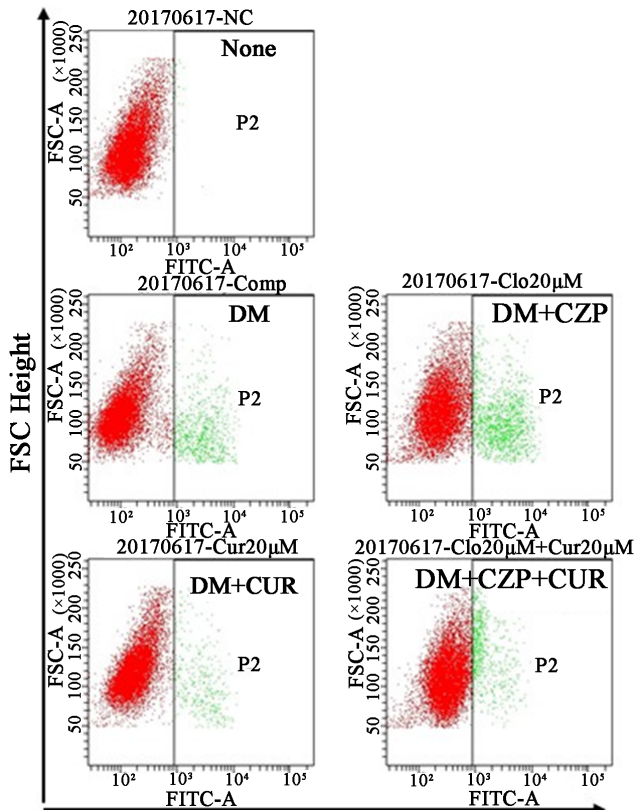

FITC Intensity (Fluorescence intensity)

(b)

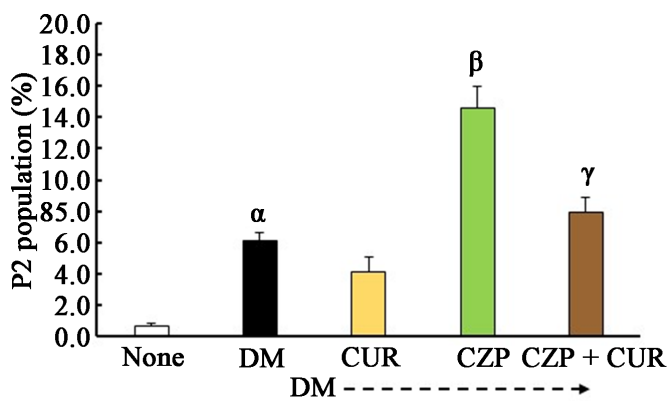

(c)

Figure 2. Alterations in results of (a) Oil Red O staining and (b) Nile red staining with flow cytometry, and (c) percentages of cells stained by Nile red (P2), in 3T3-L1 adipocytes treated with clozapine (CZP) and curcumin (CUR). (a) The photographs shown are representative of results from six independent experiments. The cells stained by Oil Red $\mathrm{O}$ were visually monitored by microscopic observation $(10 \times 20$ magnification). CZP, 20 $\mu \mathrm{M}$; CUR, $20 \mu \mathrm{M}$; (b) A representative flow cytometric analysis using Nile red staining; (c) Data are presented as mean \pm S.E. values $(\mathrm{n}=4)$. ${ }^{\alpha}$ indicates $P<0.01$ compared to the untreated cells (None). ${ }^{\beta}$ indicates $P<0.01$ compared to the cells cultured in the differentiation medium $(\mathrm{DM}){ }^{\gamma_{\text {indicates }} P}<0.01$ compared to the cells treated with CZP alone. CZP, $20 \mu \mathrm{M}$; CUR, $20 \mu \mathrm{M}$. 


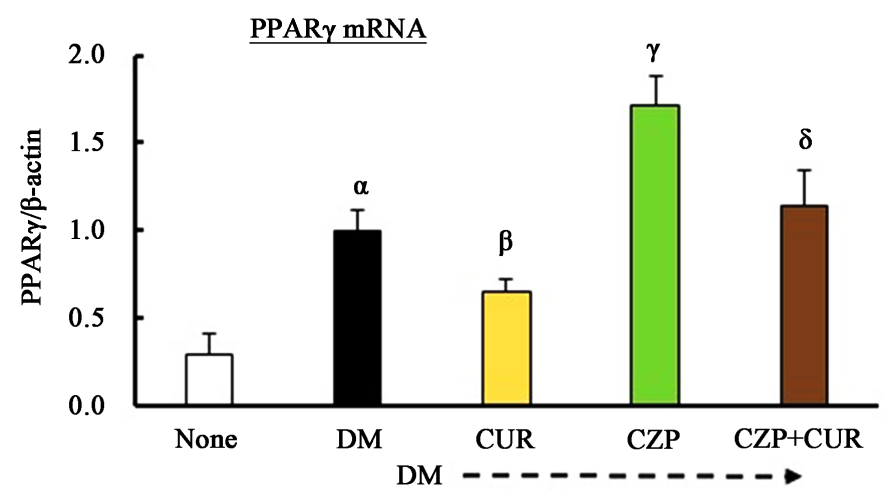

(a)

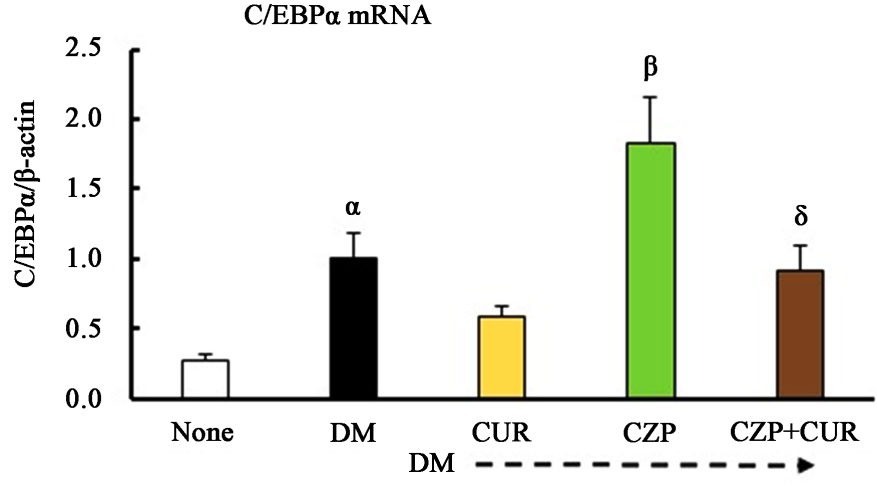

(b)

Figure 3. Alterations in the mRNA expression levels of (a) peroxisome proliferator-activated receptor $\gamma(\mathrm{PPAR} \gamma)$; and (b) CCAAT-enhancer binding protein $\alpha(\mathrm{C} / \mathrm{EBP} \alpha)$ in 3T3-L1 adipocytes treated with clozapine (CZP) and curcumin (CUR). Data are presented as the mean \pm standard error of the mean values $(\mathrm{n}=3-10)$. ${ }^{a}$ indicates $P<0.01$ compared to the untreated cells (None). ${ }^{\beta}$ indicates $P<0.05$ and $\gamma_{\text {indicates }} P<0.01 \mathrm{com}$ pared to the cells cultured in the differentiation medium (DM). ${ }^{\delta}$ indicates $P<0.05$ compared to the cells treated with CZP alone. CZP, $20 \mu \mathrm{M}$; CUR, $20 \mu \mathrm{M}$.

CZP $(20 \mu \mathrm{M})$ exposure significantly increased the mRNA expression levels of $\operatorname{PPAR} \gamma$ (1.7 fold) and C/EBP $\alpha$ (1.8 fold). In contrast, $20 \mu \mathrm{M}$ CUR in combination with $20 \mu \mathrm{M}$ CZP diminished the mRNA levels of PPAR $\gamma$ and C/EBP $\alpha$ compared to the cells treated with CZP alone, and the levels of these two mRNAs reached almost the same levels as those associated with exposure to DM alone. The same tendency was observed when PPAR $\gamma$ levels were determined by western blotting (data not shown). These results indicate that CUR interrupts the effect of CZP at the site of the C/EBP $\alpha$-PPAR $\gamma$ pathway.

\section{Discussion}

Generally, patients responding to CZP should continue maintenance treatment on their effective dose beyond the acute episode. Several studies have assessed the relationship between plasma CZP levels and clinical responses [21]. Most studies have found that a threshold plasma level of $1.1-2.6 \mu \mathrm{M}$ CZP is associated with an increased probability of a good clinical response to the drug. 
During continuous dosage of CZP, weight gain is a common side effect of this drug [1]. Short-term weight gain leads to poor adherence and other deleterious effects. However, the mechanism underlying CZP-induced weight gain is not completely understood.

The differentiation of preadipocytes into mature insulin-responsive adipocytes involves the exposure of a confluent, quiescent population of cells to a variety of effectors that activate a cascade of transcription factors, commencing with $\mathrm{C} / \mathrm{EBP} \beta$ and $\mathrm{C} / \mathrm{EBP} \delta$, and ultimately the induction of C/EBP $\alpha$ and $\operatorname{PPAR} \gamma$ expression [22] [23]. PPAR $\gamma$ is a master regulator of adipocyte differentiation. Together with $\mathrm{C} / \operatorname{EBP} \alpha, \operatorname{PPAR} \gamma$ promotes terminal differentiation by activating the expression of downstream adipocyte-specific genes.

In the present results, we showed that CZP at $5 \mu \mathrm{M}$ or less concentration potentiated TG accumulation in 3T3-L1 cells (Figure 1(a)). Additionally, compared to exposure to DM alone, $20 \mu \mathrm{M}$ CZP exposure significantly increased the mRNA expression levels of PPAR $\gamma$ and $\mathrm{C} / \mathrm{EBP} \alpha$ (Figure 3). Thus, the present study confirms that CZP at clinical levels causes body weight gain partially by directly affecting peripheral adipogenesis. It might be also possible that the CZP-induced adipogenesis is partially ascribed to enhancement of the C/EBP $\alpha$-PPAR $\gamma$ pathway.

Humans can consume up to 8 grams of CUR per day without experiencing toxic effects [24]; this makes CUR a very interesting potential preventive agent against various diseases. CUR has been reported to inhibit adipogenesis in both cellular and animal models of obesity by several research groups, including ours [9]-[15]. In addition, recent clinical trials have demonstrated that CUR can reduce blood TG levels in patients with type II diabetes [25] [26].

In the present study, the level of adipogenesis in cells treated with $20 \mu \mathrm{M} \mathrm{CZP}$ plus $20 \mu \mathrm{M}$ CUR was almost identical to that in the cells that were not treated with CZP (Figure 1(b) and Figure 2). Furthermore, the results shown in Figure 3 demonstrate that CUR reversed the CZP-induced increments in the mRNA expression of $\operatorname{PPAR} \gamma$, and $\mathrm{C} / \mathrm{EBP} \alpha$. These results suggest that because of its ability to inhibit the effects of CZP, CUR might be a potent naturally occurring compound that prevents CZP-induced weight gain, thus preventing obesity and worsening of obesity-related complications.

\section{Conclusion}

In conclusion, to our knowledge, this is the first study to show that CUR could inhibit CZP-induced weight gain and its complications via inhibition of adipocyte differentiation. Our results suggest that CUR has the potential to prevent the side effects of atypical antipsychotic drugs.

\section{Conflict of Interest}

There are no conflicts of interest to declare. 


\section{References}

[1] Nasrallah, H. (2003) A Review of the Effect of Atypical Antipsychotics on Weight. Psychoneuroendocrinology, 28, 83-96. https://doi.org/10.1016/S0306-4530(02)00114-2

[2] Casey, D.E. and Zorn, S.H. (2001) The Pharmacology of Weight Gain with Antipsychotics. Journal of Clinical Psychiatry, 62, 4-10.

[3] Minet-Ringuet, J., Even, P.C., Valet, P., Carpene, C., Visentin, V., Prevot, D., Daviaud, D., Quiqnard-Boulange, A., Tome, D. and de Beaurepaire, R. (2007) Alterations of Lipid Metabolism and Gene Expression in Rat Adipocytes during Chronic Olanzapine Treatment. Molecular Psychiatry, 12, 562-571. https://doi.org/10.1038/sj.mp.4001948

[4] Vestri, H.S., Maianu, L., Moellering, D.R. and Garvey, W.T. (2007) Atypical Antipsychotic Drugs Directly Impair Insulin Action in Adipocytes: Effects on Glucose Transport, Lipogenesis, and Antilipolysis. Neuropsychopharmacology, 32, 765-772. https://doi.org/10.1038/sj.npp.1301142

[5] Yang, L.H., Chen, T.M., Yu, S.T. and Chen, Y.H. (2007) Olanzapine Induces SREBP-1-Related Adipogenesis in 3T3-L1 Cells. Pharmacological Research, 56, 202-208. https://doi.org/10.1016/j.phrs.2007.05.007

[6] Yang, Z., Yin, J.Y., Gong, Z.C., Huang, Q., Chen, H., Zhang, W., Zhou, H.H. and Liu, Z.Q. (2009) Evidence for an Effect of Clozapine on the Regulation of Fat-Cell Derived Factors. Clinica Chimica Acta, 408, 98-104. https://doi.org/10.1016/j.cca.2009.07.021

[7] Hu, Y., Kutscher, E. and Davies, G.E. (2010) Berberine Inhibits SREBP-1-Related Clozapine and Risperidone Induced Adipogenesis in 3T3-L1 Cells. Phytotherapy Research, 24, 1831-1838. https://doi.org/10.1002/ptr.3204

[8] Sertie, A.L., Suzuki, A.M., Sertie, R.A., Andreotti, S., Lima, F.B., Passos-Bueno, M.R. and Gattaz, W.F. (2011) Effects of Antipsychotics with Different Weight Gain Liabilities on Human in Vitro Models of Adipose Tissue Distribution and Metabolism. Progress in Neuro-psychopharmacology \& Biological Psychiatry, 35, 1884-1890. https://doi.org/10.1016/j.pnpbp.2011.07.017

[9] Panahi, Y., Khalili, N., Hosseini, M.S., Abbasinazari, M. and Sahebkar, A. (2014) Lipid-Modifying Effects of Adjunctive Therapy with Curcuminoids-Piperine Combination in Patients with Metabolic Syndrome: Results of a Randomized Controlled Trial. Complementary Therapies in Medicine, 22, 851-857. https://doi.org/10.1016/j.ctim.2014.07.006

[10] Yang, Y.S., Su, Y.F., Yang, H.W., Lee, Y.H., Chou, J.I. and Ueng, K.C. (2014) Lipid-Lowering Effects of Curcumin in Patients with Metabolic Syndrome: A Randomized, Double-Blind, Placebo-Controlled Trial. Phytotherapy Research, 28, 1770-1777. https://doi.org/10.1002/ptr.5197

[11] Di Pierro, F., Bressan, A., Ranaldi, D., Rapacioli, G., Giacomelli, L. and Bertuccioli, A. (2015) Potential Role of Bioavailable Curcumin in Weight Loss and Omental Adipose Tissue Decrease: Preliminary Data of a Randomized, Controlled Trial in Overweight People with Metabolic Syndrome. Preliminary Study. European Review for Medical and Pharmacological Sciences, 19, 4195-4202.

[12] Sakuma, S., Sumida, M., Endo, H.Y., Kurita, A., Yamaguchi, A., Watanabe, T., Kohda, T., Tsukiyama, Y. and Fujimoto, Y. (2017) Curcumin Inhibits Adipogenesis Induced by Benzyl Butyl Phthalate in 3T3-L1 Cells. Toxicology and Applied Pharmacology, 329, 158-164. https://doi.org/10.1016/j.taap.2017.05.036 
[13] Ejaz, A., Wu, D., Kwan, P. and Meydani, M. (2009) Curcumin Inhibits Adipogenesis in 3T3-L1 Adipocytes and Angiogenesis and Obesity in C57/BL Mice. The Journal of Nutrition, 139, 919-925. https://doi.org/10.3945/jn.108.100966

[14] Lee, Y.K., Lee, W.S., Hwang, J.T., Kwon, D.Y., Surh, Y.J. and Park, O.J. (2009) Curcumin Exerts Antidifferentiation Effect through AMPKalpha-PPAR-Gamma in 3T3-L1 Adipocytes and Antiproliferatory Effect through AMPKalpha-COX-2 in Cancer Cells. Journal of Agricultural and Food Chemistry, 57, 305-310. https://doi.org/10.1021/jf802737z

[15] Ahn, J., Lee, H., Kim, S. and Ha, T. (2010) Curcumin-Induced Suppression of Adipogenic Differentiation Is Accompanied by Activation of Wnt/b-catenin Signaling. American Journal of Physiology, 298, C1510-C1516. https://doi.org/10.1152/ajpcell.00369.2009

[16] Pereira-Fernandes, A., Vanparys, C., Vergauwen, L., Knapen, D., Jorens, P.G. and Blust, R. (2014) Toxicogenomics in the 3T3-L1 Cell Line, a New Approach for Screening of Obesogenic Compounds. Toxicological Sciences, 140, 352-363. https://doi.org/10.1093/toxsci/kfu092

[17] Yin, L., Yu, K.S., Lu, K. and Yu, X. (2016) Benzyl Butyl Phthalate Promotes Adipogenesis in 3T3-L1 Preadipocytes: A High Content Cellomics and Metabolomics Analysis. Toxicology in Vitro, 32, 297-309. https://doi.org/10.1016/j.tiv.2016.01.010

[18] Sakuma, S., Nishioka, Y., Imanishi, R., Nishikawa, K., Sakamoto, H., Fujisawa, J., Wada, K., Kamisaki, Y. and Fujimoto, Y. (2010) cis9, trans11-Conjugated Linoleic acid Differentiates Mouse 3T3-L1 Preadipocytes into Mature Small Adipocytes through Induction of Peroxisome Proliferator-Activated Receptor $\gamma$. Journal of Clinical Biochemistry and Nutrition, 47, 167-173. https://doi.org/10.3164/jcbn.10-44

[19] Sakuma, S., Fujisawa, J., Sumida, M., Tanigawa, M., Inoda, R., Sujihera, T., Kohda, T. and Fujimoto, Y. (2012) The Involvement of Mitogen-Activated Protein Kinases in the 1 $\alpha, 25$-Dihydroxy-Cholecalciferol-Induced Inhibition of Adipocyte Differentiation in Vitro. Journal of Nutritional Science and Vitaminology, 58, 1-8. https://doi.org/10.3177/jnsv.58.1

[20] Sottile, V. and Seuwen, K. (2000) Bone Morphogenetic Protein-2 Stimulates Adipogenic Differentiation of Mesenchymal Precursor Cells in Synergy with BRL 49653 (Rosiglitazone). FEBS Letters, 475, 201-204. https://doi.org/10.1016/S0014-5793(00)01655-0

[21] Mauri, M.C., Paletta, S., Maffini, M., Colasanti, A., Dragogna, F., Di Pace, C. and Altamura, A.C. (2014) Clinical Pharmacology of Atypical Antipsychotics: An Update. EXCLI Journal, 13, 1163-1191.

[22] Morrison, R.F. and Farmer, S.R. (1999) Insights into the Transcriptional Control of Adipocyte Differentiation. Journal of Cellular Biochemistry, 32-33, 59-67. https://doi.org/10.1002/(SICI)1097-4644(1999)75:32+<59::AID-JCB8>3.0.CO;2-1

[23] Rosen, E.D., Walkey, C.J. and Puigserver, P. (2000) Transcriptional Regulation of Adipogenesis. Genes \&Development, 14, 1293-1307.

[24] Cheng, A.L., Hsu, C.H., Lin, J.K., Hsu, M.M., Ho, Y.F., Shen, T.S., Ko, J.Y., Lin, J.T., Lin, B.R., Ming-Shiang, W., Yu, H.S., Jee, S.H., Chen, G.S., Chen, T.M., Chen, C.A., Lai, M.K., Pu, Y.S., Pan, M.H., Wang, Y.J., Tsai, C.C. and Hsieh, C.Y. (2001) Phase 1 Clinical Trial of Curcumin, a Chemopreventive Agent, in Patients with High-Risk or Pre-Malignant Lessons. Anticancer Research, 21, 2895-2900.

[25] Rahimi, H.R., Mohammadpour, A.H., Dastani, M., Jaafari, M.R., Abnous, K., Ghayour Mobarhan, M. and Kazemi Oskuee, R. (2016) The Effect of Nano-Curcumin on 
HbA1c, Fasting Blood Glucose, and Lipid Profile in Diabetic Subjects: A Randomized Clinical Trial. Avicenna Journal of Phytomedicine, 6, 567-577.

[26] Panahi, Y., Khalili, N., Sahebi, E., Namazi, S., Karimian, M.S., Majeed, M. and Sahebkar, A. (2017) Antioxidant Effects of Curcuminoids in Patients with Type 2 Diabetes Mellitus: A Randomized Controlled Trial. Inflammopharmacology, 25, 25-31. https://doi.org/10.1007/s10787-016-0301-4 